\title{
Mast cell-specific Cre/loxP-mediated recombination in vivo
}

\author{
Julia Scholten · Karin Hartmann • \\ Alexander Gerbaulet • Thomas Krieg • \\ Werner Müller · Giuseppe Testa $\cdot$ Axel Roers
}

Received: 8 August 2007 / Accepted: 9 October 2007 / Published online: 31 October 2007

(C) Springer Science+Business Media B.V. 2007

\begin{abstract}
Mast cells are important effectors of type I allergy but also essential regulators of innate and adaptive immune responses. The aim of this study was to develop a Cre recombinase-expressing mouse line that allows mast cell-specific inactivation of genes in vivo. Following a BAC transgenic approach, Cre was expressed under the control of the mast cell protease (Mcpt) 5 promoter. Mcpt5-Cre transgenic mice were crossed to the ROSA26-EYFP Cre excision reporter strain. Efficient Cre-mediated recombination was observed in mast cells from the
\end{abstract}

Julia Scholten and Karin Hartmann contributed equally to this work.

Supported by grants from the German Research Counsil (Deutsche Forschungsgemeinschaft, RO 2133/2-2) to A.R. and K.H. and the Koeln Fortune Program/Faculty of Medicine, University of Cologne, to A.R. and K.H.. The authors have no conflict of interest

J. Scholten · K. Hartmann · A. Gerbaulet .

T. Krieg · A. Roers $(\bowtie)$

Department of Dermatology, University of Cologne,

Kerpener Str. 62, 50937 Cologne, Germany

e-mail: axel.roers@uni-koeln.de

W. Müller

Faculty of Life Sciences, University of Manchester,

Simon Building, Brunswick Street, Manchester M13 9PL, UK

G. Testa

European Institute of Oncology, Via Adamello, 16, Milan 20139, Italy peritoneal cavity and the skin while only minimal reporter gene expression was detected outside the mast cell compartment. Our results show that the Mcpt5 promoter can drive Cre expression in a mast cell-specific fashion. We expect that our Mcpt5-Cre mice will be a useful tool for the investigation of mast cell biology.

Keywords Mast cells · Conditional gene targeting . Cre/lox $P$-mediated recombination .

Cre transgenic mice

\section{Introduction}

Mast cells are central effector cells in type I allergy (Kawakami and Galli 2002; Metcalfe et al. 1997), but have recently been shown to be important initiators 
and effectors also of innate immunity as well as modulators of adaptive immune responses (Galli et al. 2005a, b; Marshall and Jawdat 2004). Many reports demonstrated a role of mast cells in host defence against pathogens (Dawicki and Marshall 2007; Echtenacher et al. 1996; Malaviya et al. 1996) and implicated a function of these cells in wound healing, tissue remodeling and transplant tolerance (Lu et al. 2006; Trautmann et al. 2000; Weller et al. 2006). A pathogenic role of mast cells was discussed in rheumatoid arthritis, systemic sclerosis, multiple sclerosis and atherosclerosis (Bachelet et al. 2006; Irani et al. 1992; Lee et al. 2002; Secor et al. 2000; Sun et al. 2007).

Investigation of mast cell biology was severely hampered by the scarcity of these cells in tissues. Experimental systems that have widely been used are in vitro analysis of mast cell lines or mast cells differentiated in vitro from bone marrow (BMMC). In vivo analysis of the function of genes in mast cells until today relied on the reconstitution of mast celldeficient rodents with mast cells derived from bone marrow or hematopoietic cells of gene-deficient animals or from gene-deficient embryonic stem cells (Kitamura et al. 1978; Nakano et al. 1985; Tsai et al. 2002, 2000). These systems yielded valuable information, but suffer important limitations. In the mouse lines $k i t^{W / W-v}$ and $k i t^{W-s h / W-s h}$, which are commonly used for reconstitution experiments, spontaneous mutations of the kit gene coding region or its regulatory elements result in reduced activity of the kit receptor that controls development and survival of mast cells (Galli et al. 2005b; Grimbaldeston et al. 2005). In addition to mast cell-deficiency, $\mathrm{kit}^{W / W-v}$ animals are characterized by sterility, anemia, absence of melanocytes and interstitial cells of Cajal, a high incidence of dermatitis, papillomas of the forestomach, gastric ulcers and dilation of the duodenum (Galli et al. 2005b). kit ${ }^{W-s h}$ animals, which lately are being used instead of $k i t^{W / W-v}$ mice, seem to feature a more narrow defect with deficiency for mast cells, melanocytes, and interstitial cells of Cajal (Grimbaldeston et al. 2005). The transfer of in vitro cultivated mast cells into mast cell-deficient animals by intradermal, intraperitoneal or intravenous injections can result in mast cell numbers, which, dependent on the route of cell transfer and the anatomical site, can approach normal mast cell density, but often remain considerably lower with significant variability (Grimbaldeston et al. 2005; Tsai et al. 2005).

The Cre/loxP recombination system represents a powerful tool that allows for conditional, e.g. cell type-specific, inactivation of genes in the mouse (Rajewsky et al. 1996). Since the first description of in vivo mutagenesis using the Cre/loxP system $(\mathrm{Gu}$ et al. 1994), an impressive number of floxed mouse lines has been generated. Herein, we report the first Cre transgenic line allowing mast cell-specific gene inactivation in vivo.

\section{Material and methods}

Construction of the transgene and generation of transgenic mice

The construct was based on a bacterial artificial chromosome (BAC) encompassing the entire Mcpt5 gene. The BAC clone RP23-284A14 from the mouse BAC library RPCI-23 (Osoegawa et al. 2000) was obtained from RZPD (Deutsches Ressourcenzentrum für Genomforschung $\mathrm{GmbH}$, Berlin, Germany). All modifications were done by homologous recombination in E. coli (Zhang et al. 1998) and sequences of all oligonucleotides used for construction by homologous recombination are listed in Table 1. Neighbouring genes contained in the BAC were excluded by replacing several $\mathrm{kb}$ of DNA at both ends of the insert by resistance genes (Fig. 1). In a next step, a modified iCre (improved Cre, Shimshek et al. 2002) gene cassette (Testa et al. unpublished) was inserted into the Mcpt5 gene. The Cre cassette was first assembled with a loxm2-flanked neomycin-resistance cassette (neo) and flanked by homology regions (HR) for recombination into the Mcpt5 gene. This was done by subcloning the Cre cDNA into a minimal vector consisting of the origin of replication and a chloramphenicol resistance gene amplified from pACYC184 (New England Biolabs, Frankfurt, Germany). The primers used for the amplification contain the HRs for both subcloning of Cre and insertion into the Mcpt5 gene (see Table 1). In a next step, the neomycin cassette was inserted $3^{\prime}$ of $\mathrm{Cre}$ and $5^{\prime}$ of the Mcpt5 HR. The HR-Cre-Neo-HR cassette was released from the minimal vector by NotI digestion and recombined into the BAC replacing the coding part of exon 1 of the Mcpt 5 gene followed by Cre-mediated deletion of neo. 
Table 1 Primers used for transgene construction by homologous recombination

\begin{tabular}{|c|c|c|}
\hline $\begin{array}{l}\text { recombination } \\
\text { Step/ } \\
\text { Template }\end{array}$ & Primer & Primer sequence \\
\hline \multirow{2}{*}{$\begin{array}{l}\text { shaving of the T7 } \\
\text { end of vector } \\
\text { backbone } \\
\text { Template: } \\
\text { pBluescriptlIKS+ }\end{array}$} & T7HR-Amp-F促 & $\begin{array}{l}\text { 5'GCTTGACATTGTAGGACTATATTGCTCT } \\
\text { AATAAATTTGCGGCCGCTAATAGGTCTGA } \\
\text { CGGCTCAGTGGAAC }\end{array}$ \\
\hline & $\begin{array}{l}\text { InsertHR-Notl-Amp- } \\
\text { REV }\end{array}$ & $\begin{array}{l}\text { 5'TGCCTGTTGGCCTGTGGGAGCCCAGCG } \\
\text { AGGTTGGGGCCAGCAGCGGGTGCGCGG } \\
\text { CCCGCGTGCGCGGAACCCCTATTTG }\end{array}$ \\
\hline \multirow{2}{*}{$\begin{array}{l}\text { shaving of the } \\
\text { SP6 end of } \\
\text { vector backbone } \\
\text { Template: } \\
\text { psiRNA-hH1zeo }\end{array}$} & $\frac{\text { InsertHR-Nottl-Zeo- }}{\text { FOR }}$ & $\begin{array}{l}\text { 5'GGGCAGAAAGGCTCAGAAGTTGAGACT } \\
\text { CAGCAGGGCCTCAGAAAGCTGGTGCيGGي } \\
\text { CGCOCTCCCITGGAGCCTACCTAGACTCA }\end{array}$ \\
\hline & SP6HR-Zeo-REV. & $\begin{array}{l}\text { 5'TTTCTATCCTCCCGAATTGACTAGTGGG } \\
\text { TAGGCCTGGCGGCCGCCTGGCCAATGCA } \\
\text { CTGACCTCCCACATTCCCTI }\end{array}$ \\
\hline \multirow[t]{2}{*}{$\begin{array}{l}\text { sub-cloning of } \\
\text { Cre } \\
\text { Template: } \\
\text { pACYA184 }\end{array}$} & 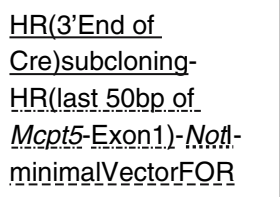 & 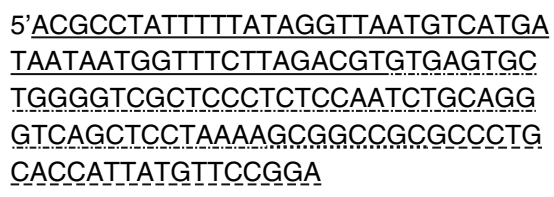 \\
\hline & $\begin{array}{l}\text { HR(5'End of } \\
\text { Cre)subcloning- } \\
\text { HR(50bpupstream of } \\
\text { Mcpt5-ATG)-Nott- } \\
\text { minimalVectorREV }\end{array}$ & 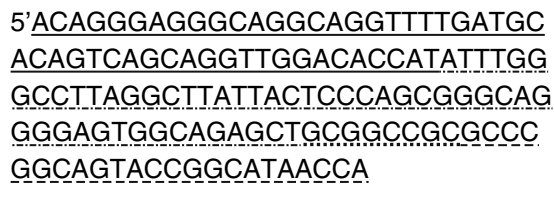 \\
\hline \multirow[t]{2}{*}{$\begin{array}{l}\text { insertion of neo } \\
\text { Template: } \\
\text { pPGK-gb2-neo }\end{array}$} & $\frac{\mathrm{HR}\left(3^{\prime} \text { End of } \mathrm{Cre}\right)}{\text { loxm2-NeoFOR }}$ & 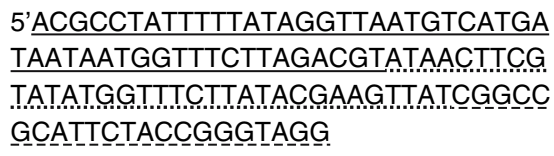 \\
\hline & $\begin{array}{l}\frac{\text { HR(last 50bp of }}{\text { Mcpt5-Exon1)-loxm2- }} \\
\text { NeoREV }\end{array}$ & 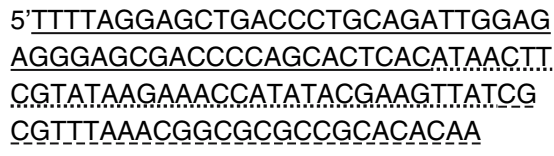 \\
\hline
\end{tabular}

Oligonucleotides used for transgene construction by homologous recombination. The respective 50 bp homology regions (HR) were included into the primers used for the amplification of selection markers or the minimal vector

The construct was purified for pronucleus injection as described by Sparwasser et al. (2004) with modifications. Briefly, the construct was separated from the BAC backbone by Not I digest and purified by gel electrophoresis and electroelution. Pronucleus injection was done by R. Naumann, MPI of Molecular Cell Biology and Genetics, Dresden, Germany. Genotyping of Mcpt5-Cre transgenic mice was performed by PCR (primers: Mcpt5-CreFor 5'ACAGTGGTATTCCCG GGGAGTGT, Mcpt5-CreRev 5' GTCAGTGCGTT CAAAGGCCA). Founder mice were bred to the ROSA26-EYFP reporter line (Srinivas et al. 2001) and five to 15 week old mice were analyzed for reporter gene expression. Animals were housed under SPF conditions and all experiments were done according to institutional guidelines. 


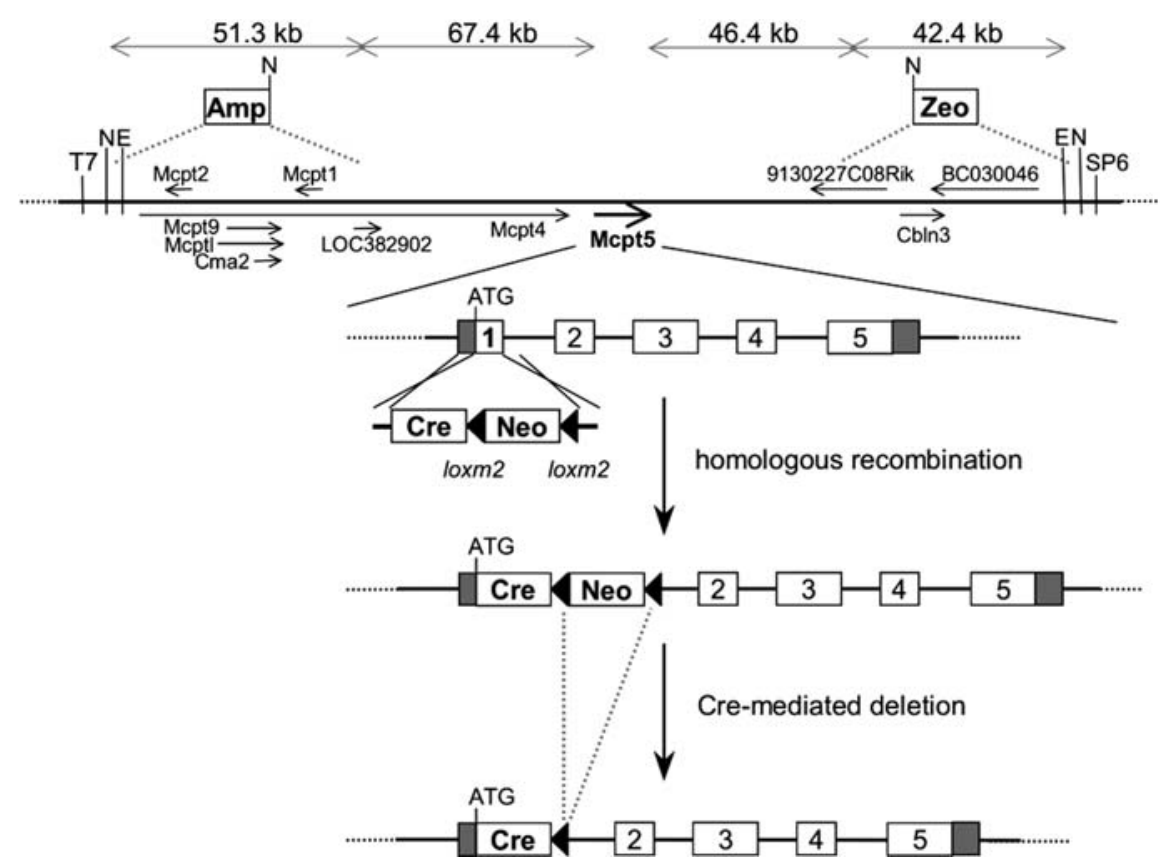

Fig. 1 Strategy of transgene construction. The BAC RP23284A14 was shortened by replacing $51.3 \mathrm{~kb}$ of insert DNA at the $\mathrm{T} 7$ end of the vector backbone and $42.4 \mathrm{~kb}$ at the SP6 end by an ampicillin (Amp) and zeocin (Zeo) resistance cassette, respectively, resulting in a residual insert length of $129 \mathrm{~kb}$. A Not $\mathrm{I}$ restriction site was inserted along with each of the

Flow cytometric analysis

Total splenocyte suspensions were separated into lymphocyte and non-lymphocyte fractions by magnetic cell sorting (MACS, Miltenyi Biotec, Bergisch Gladbach, Germany) using anti-CD3-Biotin (clone 145-2C11, BD Pharmingen), anti-Biotin MicroBeads, anti-CD19 MicroBeads and LS MACS columns (Miltenyi Biotec). Skin cell suspensions were prepared from shaved abdominal skin plus one ear pinna by mincing followed by an incubation with $2 \mathrm{mg} / \mathrm{ml}$ collagenase IV (Worthington Biochem. Corporation, Lakewood, NJ, USA) at $37^{\circ} \mathrm{C}$. Cells in peritoneal lavage as well as single cell suspensions from skin and spleen were stained with phycoerythrin (PE)-conjugated anti-CD3 (clone 145-2C11), antiCD19 (clone 1D3); anti-CD11c (clone HL3), antiCD45 (clone 30-F11) and anti-Siglec-F (clone E502440) (all from BD Pharmingen) or anti-FceRI $\alpha-\mathrm{PE}$ (clone MAR-1), allophycocyanin (APC)-conjugated resistance genes. The coding part of the first exon of Mcpt5 was replaced by a cassette comprising the Cre cassette and a loxm2flanked neomycin resistance cassette (Neo) by homologous recombination and subsequent deletion of neo by Cre-mediated deletion in E. coli. (NotI, N, EcoRI, I, arrows represent open reading frames, shaded boxes represent untranslated regions)

anti-CD117 (clone 2B8) and anti-CD49b (clone $\mathrm{D} \times 5$ ), F4/80-Biotin (clone BM8) and streptavidinPE (all from eBiosciences, SanDiego, CA) or antiGr-1-PE (clone RB6-8C5) (Miltenyi Biotech). The cells were analyzed on a FACSCalibur (BD Biosciences).

\section{Results}

Transgene construction and screening of transgenic mice for Cre expression

In order to drive Cre expression in mast cells, we used a BAC clone containing the entire Mcpt5 gene along with abundant upstream and downstream flanking DNA (Fig. 1). Neighboring genes were excluded by shortening the BAC on both ends to avoid possible effects of altered gene dosage in the transgenic mice. In a next step, the coding part of the 

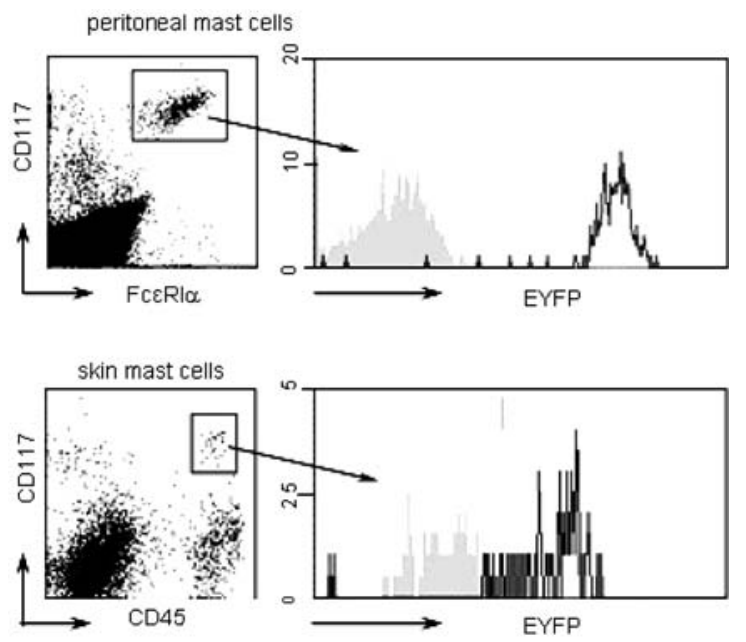

Fig. 2 Efficiency of Cre-mediated reporter gene activation in mast cells. EYFP expression is demonstrated in cells from peritoneal lavage fluid and single cell suspensions of skin of Mcpt5-Cre ROSA26-EYFP double transgenic mice. Peritoneal mast cells were stained for CD117 and FceRI $\alpha(n=7)$ and skin mast cells for CD117 and CD45 $(n=4)$. Mast cell populations were gated and their EYFP fluorescence displayed in histogram plots. The black graph represents $\mathrm{Mcpt5}$-Cre ROSA26-EYFP double transgenic mice, the shaded graph represents the Cre-negative but ROSA26-EYFP-positive control (littermates in most instances)

first exon of Mcpt5 was replaced by the Cre cassette (see Methods and Fig. 1). The construct was released from the BAC backbone by NotI digest (Fig. 1) and injected into the pronuclei of C57BL/6 oocytes. Six Mcpt5-Cre transgenic founder animals were obtained and mated to a ROSA26 reporter line (Srinivas et al. 2001) which expresses enhanced yellow fluorescent protein (EYFP) under the control of the ubiquitous ROSA26 promoter following Cre-mediated deletion of a loxP-flanked stop element. Mcpt5-Cre ROSA26EYFP double transgenic animals were analyzed for EYFP expression in peritoneal and skin mast cells by FACS as described below (Fig. 2). Reporter gene expression was detected in mast cells from three of the six founder lines. One of these lines showed EYFP expression in only $80 \%$ of peritoneal mast cells and was not investigated further. Close to $100 \%$ of peritoneal mast cells were EYFP positive in two lines, which, because of autosomal inheritance of the transgene in one line and $\mathrm{X}$-linked inheritance in the other, were called "A-Mcpt5-Cre" and "X-Mcpt5Cre”, respectively.
Efficient and mast cell-specific Cre-mediated recombination in the lines A-Mcpt5-Cre and X-Mcpt5-Cre

Highly efficient Cre-mediated activation of reporter gene expression was uniformly observed in peritoneal $\mathrm{CD} 117^{+} \mathrm{Fc} \varepsilon \mathrm{RI} \alpha^{+}$mast cells of seven A-Mcpt5-Cre ROSA26-EYFP double transgenic animals (98.7$99.6 \%$, on average $99.1 \%$, Fig. 2). In skin cell suspensions mast cells were detected in extremely low numbers, on average $0.32 \%$. (Skin mast cells were defined as $\mathrm{CD} 117^{+} \mathrm{CD} 45^{+}$cells. A staining of Fc $\varepsilon R I \alpha$ on skin mast cells was not reliable in our hands, likely due to loss of epitopes after enzymatic tissue digestion). In the five animals for which this mast cell population was investigated, the majority of the few $\mathrm{CD} 117^{+} \mathrm{CD} 45^{+}$cells gated was EYFP positive (43/47, 54/64, 32/39, 23/27 and 77/88 gated events, Fig. 2). Given that the mast cell gate will inevitably collect also some non-mast cells upon analysis of high total cell numbers (40,000 events), the percentage of skin mast cells expressing EYFP is probably close to $100 \%$. A similar efficiency of Cremediated activation of the reporter gene was observed in three male X-Mcpt5-Cre mice (not shown) whereas the two female animals analyzed showed EYFP fluorescence in only $61 \%$ and $32 \%$ of peritoneal mast cells consistent with random $\mathrm{X}$ chromosome inactivation (not shown).

In both lines, Cre-mediated activation of EYFP expression was specific for mast cells. In seven A-Mcpt5-Cre and three male X-Mcpt5-Cre animals we detected no or only minimal numbers (i.e. below $1 \%$ ) of EYFP positive cells (below 3\% in one AMcpt5-Cre animal) in hematopoietic populations other than mast cells (Fig. 3) or in non-hematopoietic cells of the skin cell suspensions (primarily keratinocytes and fibroblasts, not shown). As a control, we used mice with germline deletion of the stop element of the ROSA26-EYFP Cre excision reporter demonstrating that all non-mast cell populations analysed for reporter expression in Mcpt5-Cre mice can, in principle, express EYFP (not shown). In contrast to the seven A-Mcpt5-Cre mice (described above) showing mast cell-specific Cre-mediated recombination, one A-Mcpt5-Cre mouse displayed non-specific reporter gene expression in $15-25 \%$ of all cell types analyzed including non-hematopoietic cells of the skin (not shown). This finding likely reflects 
Fig. 3 Absence of EYFP reporter gene expression in hematopoietic cells other than mast cells. EYFP expression was analyzed in hematopoietic cells from peritoneal lavage and spleen cell suspensions of Mcpt5Cre ROSA26-EYFP double transgenic mice. In order to enrich granulocytes, splenocytes were separated into a lymphocyte and nonlymphocyte fraction by MACS. Basophils were double stained for CD49b and $\mathrm{Fc} \varepsilon \mathrm{RI} \alpha$. Macrophages, dendritic cells, neutrophils, eosinophils, B cells and T cells were stained for $\mathrm{F} 4 / 80$, CD11c, Gr-1, Siglec-F, CD19 and CD3 $\varepsilon$, respectively. The respective populations were gated and displayed in histogram plots. The black graph represents Mcpt5-Cre ROSA26-EYFP double transgenic mice, the shaded graph represents the Cre-negative but ROSA26EYFP-positive control (littermates in most instances)

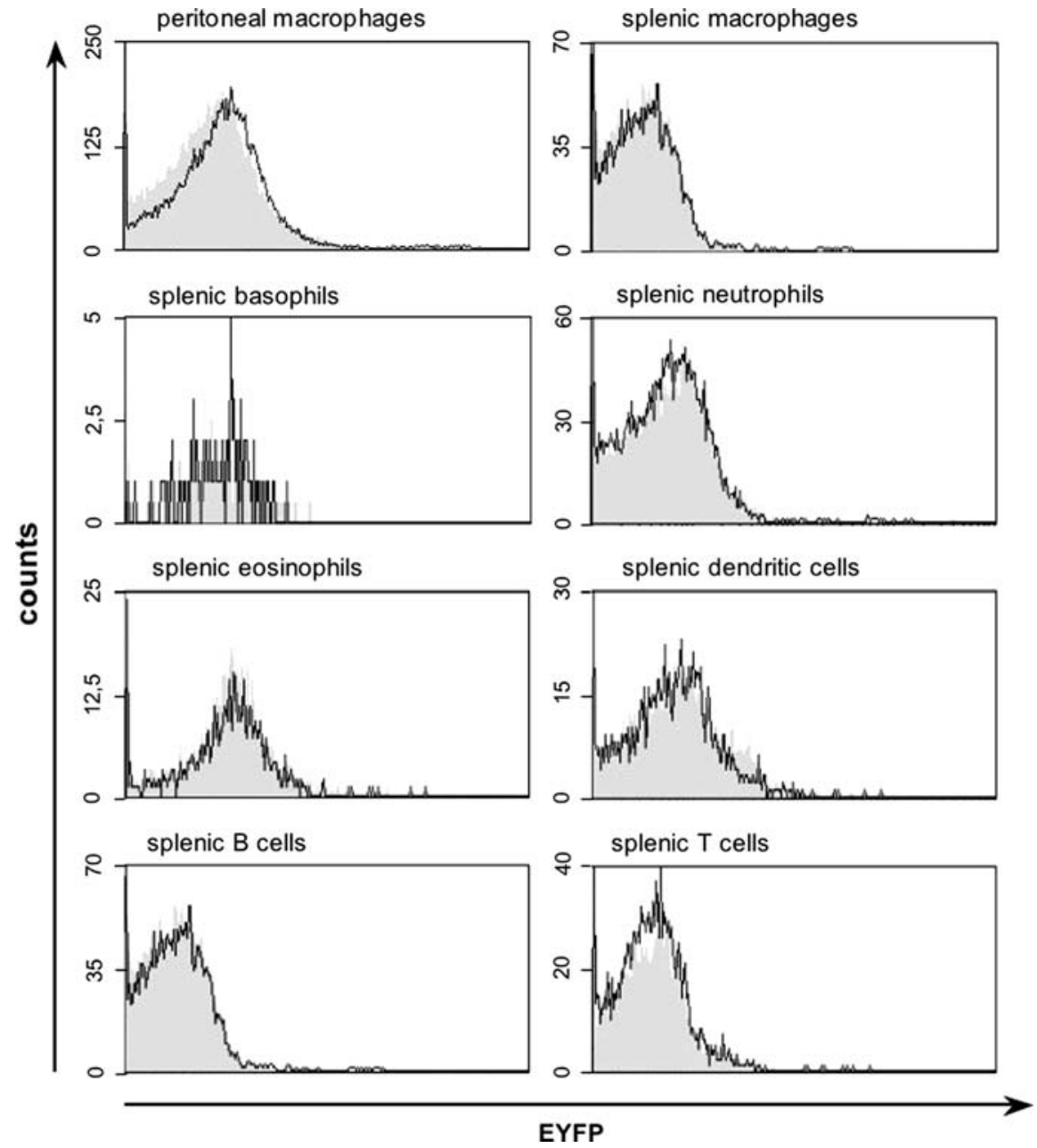

accidental early activity of the transgenic Mcpt5 promoter.

\section{Absence of significant Cre-mediated genotoxicity in mast cells of Mcpt5-Cre animals}

In order to exclude a reduced proliferative potential of mast cells in Mcpt5-Cre transgenic mice due to Cre-mediated genotoxic effects, we compared the percentage of mast cells in peritoneal lavage and the proliferation of peritoneal mast cells from Mcpt5-Cre ROSA26-EYFP double transgenic or wild-type mice in vitro. Cell suspensions obtained by peritoneal lavage contained similar numbers of mast cells in wild-type and double transgenic mice (Fig. 4a). Total peritoneal lavage cells were cultured in the presence of stem cell factor. After 23 days, these cultures contained 98\% mast cells as judged by expression of CD117 and FceRI $\alpha$ (not shown). By this time, absolute cell numbers had increased more than 200fold in both cultures (Fig. 4b). Importantly, the mast cells grown from the Mcpt5-Cre ROSA26-EYFP positive mouse uniformly expressed EYFP (not shown) ruling out an overgrowth of the culture by a (hypothetical) minor population of mast cells, which do not express Cre. These results show that Mcpt5Cre positive mast cells are not growth retarded and therefore do not seem to be significantly affected by Cre-mediated genotoxicity.

\section{Discussion}

Here, we describe a novel Cre transgenic mouse allowing mast cell-specific knock out of genes 


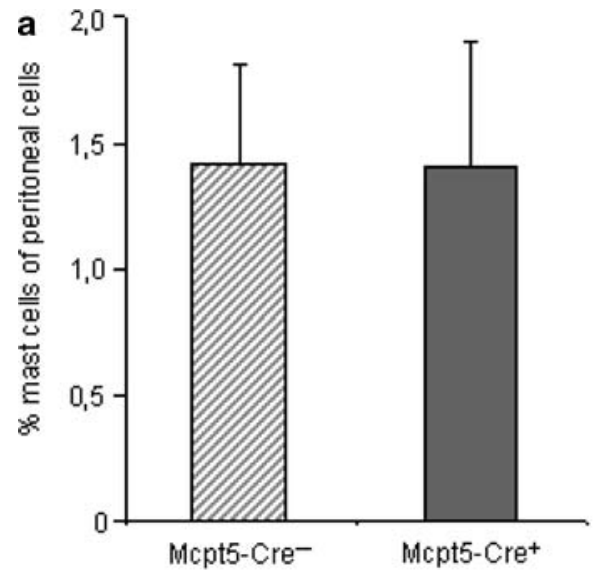

Fig. 4 Numbers and proliferative potential of peritoneal mast cells in Mcpt5-Cre transgenic mice. (a) Mast cells were quantified in peritoneal lavage fluid from control $(\mathrm{n}=9)$ and Mcpt5-Cre (7 A-Mcpt5-Cre and 3 male X-Mcpt5-Cre) mice. Mast cells were detected as $\mathrm{CD} 117^{+} \mathrm{Fc} \varepsilon \mathrm{RI} \alpha^{+}$cells by FACS. (b) Total cells from peritoneal lavage fluid from one control and one A-Mcpt5Cre ROSA26-EYFP double transgenic mouse

in vivo. We employed $\mathrm{BAC}$ transgene technology to express a Cre cassette under the control of the Mcpt5 promoter. To our knowledge, this is the first report of mast cell-specific Cre-mediated recombination in the mouse.

To date, important insights into functions of mast cells have been gained by reconstitution of mast celldeficient mice with mast cells differentiated in vitro from gene deficient bone marrow or embryonic and hematopoietic stem cells (Galli et al. 2005b; Grimbaldeston et al. 2005; Kitamura et al. 1978; Tsai et al. 2005). While this model yielded important information, inherent technical problems limit experimentation and interpretation of data in this system (Tsai et al. 2005). We expect that mast cell-specific knock out of genes using our new Cre transgenic line will greatly facilitate investigation of mast cell biology.

The two Cre transgenic lines demonstrate that the Mcpt5-promoter allows efficient and cell type-specific expression of a Cre transgene inserted into the first exon. One animal of the line A-Mcpt5-Cre (characterized by autosomal transgene inheritance) showed non-specific Cre-mediated recombination in non-mast cells while seven animals of this line did not. This finding likely reflects accidental early

\section{b}

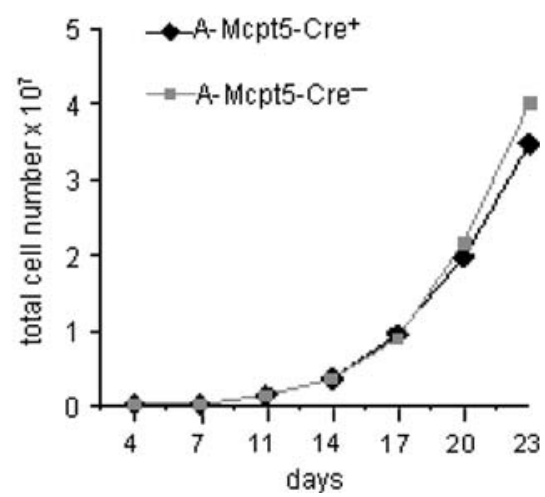

were incubated in complete Opti-MEM supplemented with $4 \%$ supernatant from $\mathrm{CHO}$ transfectants secreting murine SCF (Malbec et al. 2007). The CHO transfectants were generated by S. Lyman, Immunex, Seattle and were kindly provided by P. Dubreuil. Cell numbers were quantified at each passage every 3-4 days by counting trypan blue-excluding cells

activity of the transgenic Mcpt5 promoter, e.g. in one stem cell during the embryonic four cell stage. Future analysis will define the frequency of such events more precisely. In females of the X-Mcpt5Cre line (X-chromosomal inheritance), Cre-mediated recombination occurred in only about half of the mast cells due to inactivation of the transgene-carrying $\mathrm{X}$ chromosome. Incomplete inactivation of particular genes may be advantageous if the attenuation of a severe phenotype is desired.

Cre recombinase has been shown to mediate genotoxicity in some $\mathrm{Cre}$ transgenic or $\mathrm{Cre}$ knock in mouse strains resulting in a reduced proliferative potential or even death of Cre expressing cells (Schmidt-Supprian and Rajewsky 2007). In Mcpt5Cre mice, however, we found no difference in mast cell numbers or proliferation of mast cells ex vivo in response to stem cell factor indicating that Cremediated genome damage is not a prominent feature of these mice.

We are currently refining our system further to achieve also inducible mast cell-specific gene inactivation in adult mice. In addition, we are breeding the new lines to iDTR mice (Buch et al. 2005) aiming at diphtheria toxin-inducible ablation of the mast cell lineage in adult animals. 
Acknowledgements The authors wish to thank Tobias Haering and Carmen Berns for excellent technical assistance. We thank Dr. P. Dubreuil for providing SCF producing CHO transfectants.

\section{References}

Bachelet I, Levi-Schaffer F, Mekori YA (2006) Mast cells: not only in allergy. Immunol Allergy Clin North Am 26:407-425

Buch T, Heppner FL, Tertilt C, Heinen TJ, Kremer M, Wunderlich FT, Jung S, Waisman A (2005) A Cre-inducible diphtheria toxin receptor mediates cell lineage ablation after toxin administration. Nat methods 2:419-426

Dawicki W, Marshall JS (2007) New and emerging roles for mast cells in host defense. Curr Opin Immunol 19:31-38

Echtenacher B, Mannel DN, Hultner L (1996) Critical protective role of mast cells in a model of acute septic peritonitis. Nature 381:75-77

Galli SJ, Kalesnikoff J, Grimbaldeston MA, Piliponsky AM, Williams CM, Tsai M (2005a) Mast cells as "tunable" effector and immunoregulatory cells: recent advances. Annu Rev Immunol 23:749-786

Galli SJ, Nakae S, Tsai M (2005b) Mast cells in the development of adaptive immune responses. Nat Immunol 6:135-142

Grimbaldeston MA, Chen CC, Piliponsky AM, Tsai M, Tam SY, Galli SJ (2005) Mast cell-deficient W-sash c-kit mutant Kit $\mathrm{W}$-sh/W-sh mice as a model for investigating mast cell biology in vivo. Am J Pathol 167:835-848

Gu H, Marth JD, Orban PC, Mossmann H, Rajewsky K (1994) Deletion of a DNA polymerase beta gene segment in $\mathrm{T}$ cells using cell type-specific gene targeting. Science 265:103-106

Irani AM, Gruber BL, Kaufman LD, Kahaleh MB, Schwartz LB (1992) Mast cell changes in scleroderma. Presence of MCT cells in the skin and evidence of mast cell activation. Arthritis Rheum 35:933-939

Kawakami T, Galli SJ (2002) Regulation of mast-cell and basophil function and survival by IgE. Nat Rev Immunol 2:773-786

Kitamura Y, Go S, Hatanaka K (1978) Decrease of mast cells in W/Wv mice and their increase by bone marrow transplantation. Blood 52:447-452

Lee DM, Friend DS, Gurish MF, Benoist C, Mathis D, Brenner MB (2002) Mast cells: a cellular link between autoantibodies and inflammatory arthritis. Science 297:1689-1692

Lu LF, Lind EF, Gondek DC, Bennett KA, Gleeson MW, PinoLagos K, Scott ZA, Coyle AJ, Reed JL, Van Snick J, Strom TB, Zheng XX, Noelle RJ (2006) Mast cells are essential intermediaries in regulatory $\mathrm{T}$-cell tolerance. Nature 442:997-1002

Malaviya R, Ikeda T, Ross E, Abraham SN (1996) Mast cell modulation of neutrophil influx and bacterial clearance at sites of infection through TNF-alpha. Nature 381:77-80

Malbec O, Roget K, Schiffer C, Iannascoli B, Dumas AR, Arock M, Daëron M (2007) Peritoneal cell-derived mast cells: an in vitro model of mature serosal-type mouse mast cells. J Immunol 178:6465-6475

Marshall JS, Jawdat DM (2004) Mast cells in innate immunity. J Allergy Clin Immunol 114:21-27

Metcalfe DD, Baram D, Mekori YA (1997) Mast cells. Physiol Rev 77:1033-1079

Nakano T, Sonoda T, Hayashi C, Amatodani A, Kanayama Y, Yamamura T, Asai H, Yonezawa T, Kitamura Y, Galli SJ (1985) Fate of bone marrow-derived cultured mast cells after intracutaneous, intraperitoneal, and intravenous transfer into genetically mast cell-deficient $\mathrm{W} / \mathrm{Wv}$ mice. Evidence that cultured mast cells can give rise to both connective tissue type and mucosal mast cells. J Exp Med 162:1025-1043

Osoegawa K, Tateno M, Woon PY, Frengen E, Mammoser AG, Catanese JJ, Hayashizaki Y, de Jong PJ (2000) Bacterial artificial chromosome libraries for mouse sequencing and functional analysis. Genome Res 10:116-128

Rajewsky K, Gu H, Kuhn R, Betz UA, Muller W, Roes J, Schwenk F (1996) Conditional gene targeting. J Clin Invest 98:600-603

Schmidt-Supprian M, Rajewsky K (2007) Vagaries of conditional gene targeting. Nat Immunol 8:665-668

Secor VH, Secor WE, Gutekunst CA, Brown MA (2000) Mast cells are essential for early onset and severe disease in a murine model of multiple sclerosis. J Exp Med 191:813-822

Shimshek DR, Kim J, Hübner MR, Spergel DJ, Buchholz F, Casanova E, Stewart AF, Seeburg PH, Sprengel R (2002) Codon-improved Cre recombinase (iCre) expression in the mouse. Genesis 32:19-26

Sparwasser T, Gong S, Li JY, Eberl G (2004) General method for the modification of different BAC types and the rapid generation of $\mathrm{BAC}$ transgenic mice. Genesis 38:39-50

Srinivas S, Watanabe T, Lin CS, William CM, Tanabe Y, Jessell TM, Costantini F (2001) Cre reporter strains produced by targeted insertion of EYFP and ECFP into the ROSA26 locus. BMC Dev Biol 1:4

Sun J, Sukhova GK, Wolters PJ, Yang M, Kitamoto S, Libby P, Macfarlane LA, Clair JM, Shi GP (2007) Mast cells promote atherosclerosis by releasing proinflammatory cytokines. Nat Med 13:719-724

Trautmann A, Toksoy A, Engelhardt E, Brocker EB, Gillitzer $\mathrm{R}$ (2000) Mast cell involvement in normal human skin wound healing: expression of monocyte chemoattractant protein-1 is correlated with recruitment of mast cells which synthesize interleukin-4 in vivo. J Pathol 190: 100-106

Tsai M, Grimbaldeston MA, Yu M, Tam SY, Galli SJ (2005) Using mast cell knock-in mice to analyze the roles of mast cells in allergic responses in vivo. Chem Immunol Allergy 87:179-197

Tsai M, Tam SY, Wedemeyer J, Galli SJ (2002) Mast cells derived from embryonic stem cells: a model system for studying the effects of genetic manipulations on mast cell development, phenotype, and function in vitro and in vivo. Int J Hematol 75:345-349

Tsai M, Wedemeyer J, Ganiatsas S, Tam SY, Zon LI, Galli SJ (2000) In vivo immunological function of mast cells derived from embryonic stem cells: an approach for the 
rapid analysis of even embryonic lethal mutations in adult mice in vivo. Proc Natl Acad Sci U S A 97:9186-9190

Weller K, Foitzik K, Paus R, Syska W, Maurer M (2006) Mast cells are required for normal healing of skin wounds in mice. FASEB J 20:2366-2368
Zhang Y, Buchholz F, Muyrers JPP, Stewart AF. (1998) A new logic for DNA engineering using recombination in Escherichia coli Nat Genet 20:123-128 